\title{
Estimating seabird densities from vessel transects: distance sampling and implications for strip transects
}

\author{
Robert A. Ronconi ${ }^{1,2, *}$, Alan E. Burger ${ }^{1}$ \\ ${ }^{1}$ Department of Biology, University of Victoria, PO Box 3020 Stn CSC, Victoria, BC, V8W 3N5, Canada \\ ${ }^{2}$ Present address: Department of Biology, Dalhousie University, 1355 Oxford St., Halifax, Nova Scotia, B3H 4J1, Canada
}

\begin{abstract}
Vessel-based transects have been a mainstay of seabird research for decades, yet there has been surprisingly little effort to evaluate the detectability of seabirds within strip transects. Distance sampling methods offer an opportunity to quantify detectability and assess the proportions of birds on the water that may be missed during strip transects. Three summers of line-transect surveys were analyzed using the program Distance to model detection functions of 6 seabird taxa (marbled murrelet Brachyramphus marmoratus, rhinoceros auklet Cerorhinca monocerata, common murre Uria aalge, pigeon guillemot Cepphus columba, pelagic cormorant Phalacrocorax pelagicus, gulls Larus spp.). We tested the effects of covariates (year, observers, sea state, and cluster size) on detection function estimation. Year and observer were the most important covariates for some but not all species. For a $300 \mathrm{~m}$ wide transect ( $150 \mathrm{~m}$ on either side), 20 to $80 \%$ of birds were detected, depending on species, year, and observer. Detectability was highest for cormorants (60 to $90 \%$ ) and fairly similar among other species (typically 40 to $60 \%$ ). Sea state had a significant effect on encounter rate for murrelets suggesting that $g(0)$, detection probability near the transect line, may be $<1$ when wave height increases. These data emphasize that a high proportion of birds on the water remain undetected during strip-transect surveys. It is important that surveys develop independent estimates of detection probability to account for detectability among species, years, observers, vessel types/speed, and viewing conditions. The application of distance sampling to seabird surveys can provide more accurate abundance and population estimates, which can improve conservation and management efforts.
\end{abstract}

KEY WORDS: Abundance estimates $\cdot$ Detectability $\cdot$ Distance sampling $\cdot$ Line transects $\cdot$ Observer bias $\cdot$ Seabirds $\cdot$ Surveys

\section{INTRODUCTION}

Reliable census techniques and accurate assessments of animal densities are fundamental to wildlife research, monitoring and estimation of population size (Braun 2005). Vessel-based transect surveys have been a part of seabird research for nearly a century (Jespersen 1924, Wynne-Edwards 1935) and a mainstay of seabird biology since the 1960s (Brown et al. 1974, Tasker et al. 1984). Transect surveys using standardized protocols (Tasker et al. 1984) have contributed substantially to understanding seabird ecology (>150 peer-reviewed publications found with a Web-ofScience search). Despite their ubiquitous use in seabird research, vessel-based transects are not without methodological problems and biases. This is of particular interest when monitoring populations of threatened species or in conducting environmental impact studies for seabirds at sea. Of central importance are factors affecting accuracy of density and abundance estimates (e.g. Hyrenbach 2001, Spear et al. 2004).

In all studies, some birds on the water are not detected, leading to underestimates of seabird densities. With standardized strip-transect surveys (Tasker et 
al. 1984) the basic assumption is that all objects within the strip are detected. However, distance sampling methodology has shown empirically that this assumption is usually violated because individuals closer to the transect line have a higher probability of detection than those further from the line (Buckland et al. 2001, 2004). Rather than counting organisms within a predetermined transect width, distance sampling records the perpendicular distance of individuals (or clusters/ flocks) from the transect line. Based on these distances, Distance software (Thomas et al. 2006) provides estimates of the proportions of organisms missed during surveys, thus allowing more accurate density estimates.

Marine mammal and sea turtle researchers have been developing and employing distance sampling protocols for decades (Burnham et al. 1980, Laake et al. 1997, Beavers \& Ramsey 1998) which have now become the backbone of robust density and population estimates (Forcada et al. 2004, Slooten et al. 2004, Gomez de Segura et al. 2006). Distance sampling has been advocated to improve the reliability of bird surveys (Rosenstock et al. 2002, Thompson 2002), yet transect surveys for marine birds have been slow to adopt this method. The one exception has been with marbled murrelets (Brachyramphus marmoratus) where distance sampling has been readily used (Becker et al. 1997, Evans Mack et al. 2002, Peery et al. 2004, 2006, 2007). Newer monitoring programs have been amenable to adopting distance sampling protocols (RIC 2001, Raphael et al. 2007), but established and longer-term seabird survey programs have used striptransect and are hesitant to change protocols (Pyle 2007). Several European programs (Komdeur et al. 1992, Camphuysen et al. 2004) and one Canadian program (Eastern Canadian Seabirds At Sea) have adopted distance sampling protocols for seabird surveys.

Distance sampling methodology has been thoroughly developed (Buckland et al. 2001, 2004) and evaluated (Kulbicki \& Sarramegna 1999, le Mar et al. 2001, Norvell et al. 2003). Our goal is not to validate the technique further but rather to demonstrate its relevance for seabird surveys and to examine the variability in detection probabilities for a variety of species and conditions. We assessed the effects of year, observer bias, sea state, and cluster size on seabird detection functions. We compared parameter estimates showing the proportion of birds detected for fixed-width strip transects of 200 or 300 m (100 or $150 \mathrm{~m}$ on either side of the boat). The results and methods are relevant for other vessel-based surveyors who wish to use distance sampling to improve the accuracy of seabird density estimates, including those based on strip transects.

\section{MATERIALS AND METHODS}

Study area and organisms. Line-transect surveys were conducted between 20 May and 8 August in 3 years (2004-2006). The study area was located in the West Coast Trail unit of Pacific Rim National Park on the southwestern coast of Vancouver Island, British Columbia, Canada (Ronconi \& Burger 2008). This is a $65 \mathrm{~km}$ stretch of coast exposed to the Pacific Ocean. All surveys were conducted within $2 \mathrm{~km}$ from land in waters $<40$ m deep.

Sample sizes for distance sampling analysis were sufficient to investigate 6 taxa: 4 Alcidae (marbled murrelet, rhinoceros auklet Cerorhinca monocerata, common murre Uria aalge, pigeon guillemot Cepphus columba), one cormorant (pelagic cormorant Phalacrocorax pelagicus), and gulls (glaucous-winged gull Larus glaucescens; and California gull L. californicus; pooled as Larus spp.). This range of species provides a representative array for distance sampling analysis typical of the communities encountered in coastal waters of the northern hemisphere: pursuit divers (alcids/cormorants) vs. surface feeders (gulls), small (murrelets/guillemot/auklet) vs. large birds (murre/ cormorant/gull), and drab (murrelet/auklet) vs. conspicuous alcids (guillemot/murre).

Survey methods. All surveys were conducted from a $5 \mathrm{~m}$ rigid-hull inflatable boat traveling at approximately $10 \mathrm{~km} \mathrm{~h}^{-1}$. Observer height was 1.5 to $2 \mathrm{~m}$ above the water surface. Surveys were conducted with paired observers (Evans Mack et al. 2002) at the bow, each scanning one side of the transect line from directly ahead to $90^{\circ}$ abeam. Search pattern included equal effort through the $90^{\circ}$ arc and out to about $300 \mathrm{~m}$ from the transect line. Although flying birds were recorded as well, search effort emphasized birds on the water because most species examined were pursuit divers. Observers on each side were independent but communicated to each other about birds near or on the transect line so as not to double count these groups. All observations were recorded on hand-held audio recorders and later transcribed.

Distance sampling analysis was restricted to birds on the water. Surveys followed distance sampling protocols (Buckland et al. 2001) recording bird clusters (individual birds or groups of birds of the same species), perpendicular distance from the transect line (estimated at the time of first detection), and cluster size. Although Buckland et al. (2001) recommend recording angles to birds and distance at first detection (radial distance), we estimated perpendicular distance from the transect line which, for murrelets, is as accurate as radial distances (Raphael et al. 1999). Birds were considered to be in clusters if they were within $2 \mathrm{~m}$ of each other, or if they were slightly further apart 
and were foraging together or exhibiting similar behavioral cues (Becker et al. 1997). Observers were trained in distance estimation by towing a line with 3 buoys spaced at 10,25, and $50 \mathrm{~m}$ behind the boat. Other calibration techniques with hand-held calipers (Heinemann 1981) are not well suited for small vessels with observer height close to sea level. The buoy line was used for the first 3 weeks each year, until observers were competent at estimation to $\pm 10 \mathrm{~m}$, and used again periodically several days per month. This training method emphasized consistency among observers in distance estimation. There were multiple observers each year (2 in 2004 and 3 in 2005 and 2006) with one observer (R.A.R.) consistent in all years.

During each survey we collected environmental data on viewing conditions, and restricted surveys to periods of low swell $(<1.5 \mathrm{~m})$ and low winds (Beaufort sea state $\leq 3)$. For analysis we coded sea state into 2 categories as per Becker et al. (1997): excellent/very good (Beaufort 0 to 1) and good/fair (Beaufort 2 to 3). Most observations were collected on days without fog and on a few days when fog was patchy and visibility to at least $100 \mathrm{~m}$. Glare had little effect on data collection; morning glare was minimal because transects were close to shore where the sun rose over land and few transects were conducted late in the day when late afternoon glare was a problem.

Transects layout included 2 designs: zig-zags and parallel lines perpendicular to the shore. The zig-zag transect layout was systematic to cover the length of the study area and was bounded by the 5 and $20 \mathrm{~m}$ depth contours, the latter delineating the seaward park boundary. Depending on shoreline complexity and navigation hazards, zig-zag legs were on average $1.6 \mathrm{~km}$ long (range 0.9 to $2.9 \mathrm{~km}$ ) and typically bisected the coastline at $45^{\circ}$ angles. Total zig-zag length was $77 \mathrm{~km}$ which was surveyed 5 to 6 times in 2005 and 2006. In some sectors of the study area, we established a series of parallel transects, spaced $500 \mathrm{~m}$ apart and oriented perpendicular to shore. These transects were bounded by the 5 and $40 \mathrm{~m}$ depth contours (approx. 1 to $2 \mathrm{~km}$ offshore). This design was used at one site in 2004 (total length $13.4 \mathrm{~km} ; 7$ parallel legs) and expanded to 6 other sites in 2005 and 2006 (mean length $7.0 \mathrm{~km}$, range 5.2 to $8.3 \mathrm{~km}$; 3 to 4 parallel legs). All data were pooled for analysis.

Calculating densities from transects. We present a basic equation useful for the interpretation of results in this study (see also Buckland et al. 2001 for complete distance sampling equations). The basic estimate of density $\hat{D}$ for objects in a study area can be calculated by the number of objects counted $n$ divided by the area surveyed $a$. In the case of a strip-transect line, the area surveyed is equal to the strip width $2 w$ multiplied by the total length $L$ of the transect. Here $w$ represents the width on one side of the boat (e.g. $150 \mathrm{~m}$ ) and is multiplied by 2 when observers are counting birds on both sides of the boat.

$$
\hat{D}=\frac{n}{2 w L}
$$

With line transects, however, not all of the objects within the survey area a are detected, thus $\hat{P}_{a}$ estimated with the Distance software, is included to represent the proportion of birds detected within the survey area. When the objects are groups of organisms, an estimate of mean group size $E(\mathrm{~s})$ is also introduced as a multiplier in the equation:

$$
\hat{D}=\frac{n E(s)}{2 w L \hat{P}_{a}}
$$

Buckland et al. (2001) present several methods for unbiased estimates of $E(\mathrm{~s})$. We used the regression estimator which estimates mean cluster size by the predicted mean cluster size on the transect line, where object detection is certain (Buckland et al. 2001).

Other multipliers may also be included in the equation to correct discrepancies in the detection function. One important multiplier is $g(0)$, the probability of detecting a bird on or near the transect line. A critical assumption of distance sampling is that all objects on or near the transect line are detected, i.e. $g(0)=1$, however if this assumption is not met then $g(0)$ can be introduced into the equation as:

$$
\hat{D}=\frac{n E(s)}{2 w L \hat{P}_{a}} \frac{1}{g(0)}
$$

Assumptions of distance sampling. For effective distance sampling analysis, there are 3 basic assumptions that should not be violated (Buckland et al. 2001, Rosenstock et al. 2002).

Assumption 1: all birds on the transect line are detected: $g(0)=1$, where $g(0)$ is the probability of detecting birds at distance zero. Few studies validate this critical assumption (Bächler \& Liechti 2007). There are 2 reasons why diving birds, or other air-breathing marine divers, may not be detected: (1) availability bias (animals are missed because they are submerged) and (2) perception bias (visible animals are missed for other reasons e.g. sea state, distance) (Marsh \& Sinclair 1989, Laake et al. 1997). Availability bias should be minimal for seabirds which spend a high proportion of time visible on the surface, compared to marine mammals. Average dive times for murrelets are only $25 \mathrm{~s}$ (Jodice \& Collopy 1999), therefore at our boat speed $\left(10 \mathrm{~km} \mathrm{~h}^{-1}\right)$, birds that dove $<70 \mathrm{~m}$ ahead of the boat would resurface after the boat had passed. We expect to be able to detect most birds within this distance before they dive. Average dive times for other species 
are similar or slightly longer, but these are larger and more conspicuous species. Some birds dive in response to approaching boats, thus additionally affecting availability bias. Murrelets typically dive when a boat approaches closer than $40 \mathrm{~m}$ (Bellefleur et al. 2009), but at this response distance we expect that most birds were detected prior to escape by diving. Evans Mack et al. (2002) tested visibility bias for marbled murrelets finding that $g(0)$ ranged from $0.84-0.93$ with double observers. However, average boat speed in their study was $\left(20 \mathrm{~km} \mathrm{~h}^{-1}\right)$, twice that of our study, therefore, $g(0)$ may be closer to 1 in our study. Nevertheless, we conducted a test of potential sea state effects on $g(0)$ (see 'Data analysis' below).

Assumption 2: birds are detected prior to evasive movements. We recorded perpendicular distance to the transect line at the time of first detections, therefore typically before the boat was close enough to cause evasive movements. Elsewhere, murrelets typically moved $<10 \mathrm{~m}$ before detection for distance sampling (Brennan 2000).

Assumption 3: distances are measured accurately. We maintained the accuracy of distance estimation by thorough and repeated training ('Survey methods', above), but because distances in the field were rounded to $10 \mathrm{~m}$ increments, our precision is limited to this scale, and therefore distances were grouped into bins for analysis (Buckland et al. 2001).

Data analysis. Data were analyzed using Distance 5.0 Release 2 (Thomas et al. 2006) and the multiple covariates distance sampling (MCDS) engine. We followed analysis guidelines outlined by Buckland et al. (2001) which include exploratory analysis, model selection, and final analysis and inference.

Exploratory analysis included plotting of histograms of various groupings (distance bins), truncation of data, and inspection of cluster-size bias. Histograms of various bin sizes were constructed in SPSS 15.0. The minimum bin size of $10 \mathrm{~m}$ indicated heaping or rounding errors, but bins of $20 \mathrm{~m}$ increments (Fig. 1) showed a broad shoulder (most detections near the transect line), little evidence of evasive movements, and evidence of outliers beyond $150 \mathrm{~m}$ (Buckland et al. 2001). Consequently analyses were done using distance bins of $20 \mathrm{~m}(0-20,21-40$, etc.). Distance analysis allows for uneven bin sizes when required and the final bin was only $10 \mathrm{~m}$ wide (141 to $150 \mathrm{~m}$ ) to accommodate the selected truncation distance (see below).

Buckland et al. (2001) recommend data truncation to eliminate outliers and improve model fitting. We selected a truncation of $150 \mathrm{~m}$ on either side of the boat (i.e. overall a $300 \mathrm{~m}$ band) for 2 reasons. First, $150 \mathrm{~m}$ falls within the range of truncation from previous studies using distance sampling with murrelets $(160 \mathrm{~m}$, Becker et al. 1997; 120 m, Peery et al. 2006). Second, a $150 \mathrm{~m}$ width on both sides has been the standard for annual surveys conducted by Parks Canada in our study area since 1993 (Burger et al. 2008) and for other seabird surveys off the British Columbia coast (Burger et al. 2004). Note that $300 \mathrm{~m}$ bands (typically on one side of the vessel) have been the standard protocol (Tasker et al. 1984), but this distance was selected particularly to count flying birds. A 150 m wide transect is more appropriate for small boats (this study) and reduces the scanning time in areas far way from the boat, thus decreasing the likelihood of missing birds near the midline.

Cluster-size bias frequently occurs in survey work because at greater distances from the transect line larger clusters of birds are more easily detected than smaller ones (Buckland et al. 2001). Unbiased estimation of mean cluster size is essential for accurate density estimation. We tested for cluster-size bias by looking at correlations between cluster size and distance from transect line for different truncation distances $(300,150,100,50 \mathrm{~m})$ using SPSS 15.0. When clustersize bias was detected, regression techniques were used to determine an unbiased cluster size estimate for density calculations in subsequent analyses (Buckland et al. 2001).

The program Distance allows several key functions and series expansion terms for modeling the detection function. For each species, we tested the following models (and series expansion terms) which may be used in MCDS: half-normal (cosine or hermite polynomial) and hazard-rate models (cosine or simple polynomial). Model fit and ranking was assessed using Akaike's Information Criterion with correction for small samples sizes $\left(\mathrm{AIC}_{\mathrm{c}}\right.$ ) (Burnham \& Anderson 2002). For all species, except pigeon guillemot, hazard-rate models provided the best fit to the data (lowest $\mathrm{AIC}_{\mathrm{C}}$ score). For pigeon guillemots, the half-normal model fit best though the hazard-rate model also fit the data well $\left(\Delta \mathrm{AIC}_{\mathrm{C}}<2\right)$. For gulls, cormorants and guillemots, series expansion terms were not included in the best fit model. Cosine series expansion was included in the best fit model for murrelets and simple-polynomial terms were included in the best fit models for auklets and murres. Hazard-rate models with or without appropriate series expansion terms were used for subsequent analyses.

MCDS analyses were conducted to test for effects of the covariates year, observers, sea state and cluster size on the estimation of detection functions for each species. The year covariate was assessed at 3 levels for murrelets $(2004,2005,2006), 2$ levels for murres and cormorants $(2005,2006)$, and not tested for other species due to sample size constraints. We excluded one observer (Obs 2) from guillemot, cormorant and gull models because $n<5$ observations for each spe- 

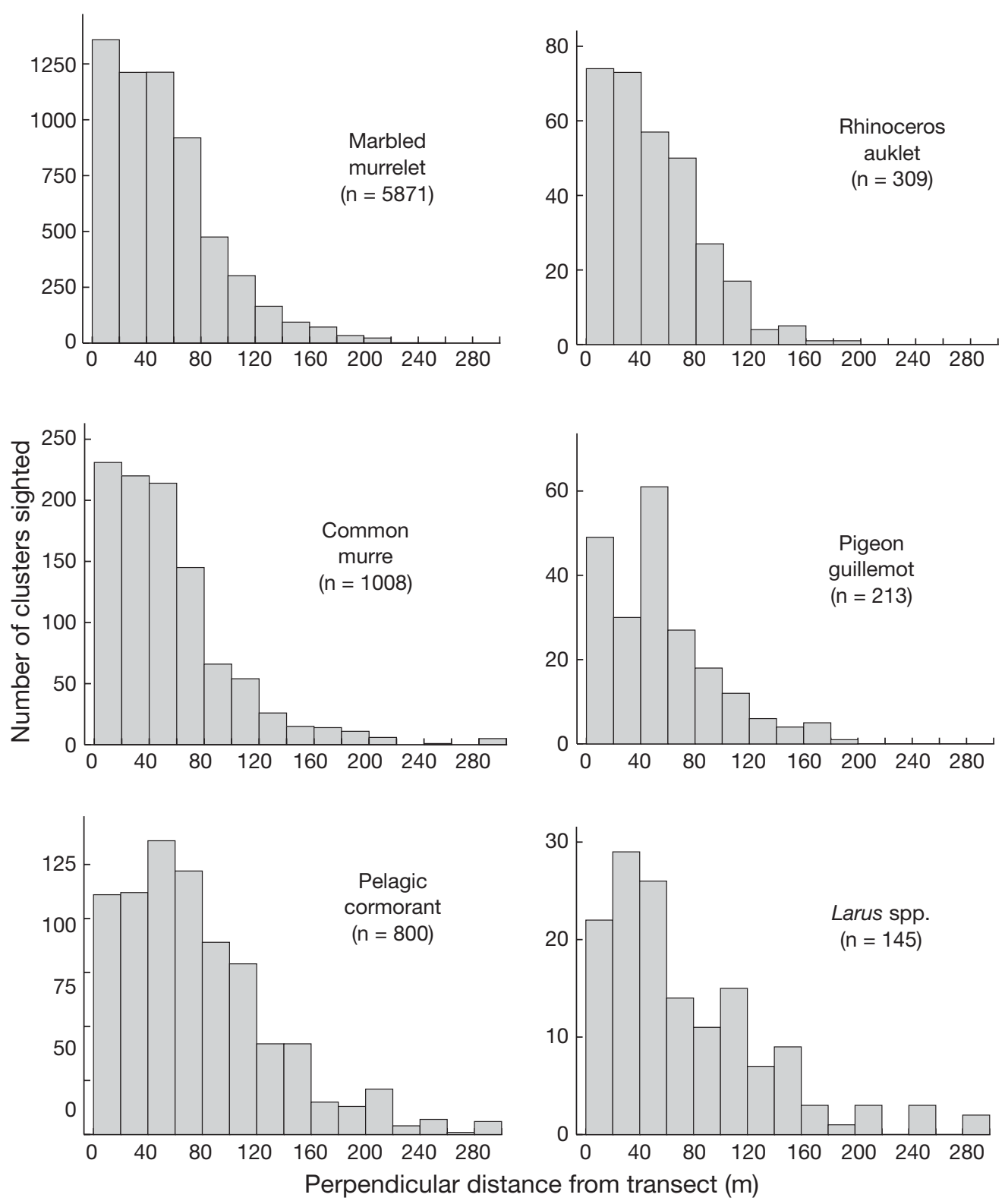

Fig. 1. Brachyramphus marmoratus, Cerorhinca monocerata, Uria aalge, Cepphus columba, Phalacrocorax pelagicus and Larus spp. Detection distance of seabird clusters (groups/flocks) sighted on the water during vessel-based transects, binned in 20 m intervals

cies. Sea state was coded at 2 levels for analysis: Beaufort sea states 0 to 1 and 2 to 3 (described in 'Survey methods', above). Because fitting the detection function with multiple covariates can be computationally difficult, often resulting in model convergence failure, we followed steps outlined in the Distance User's Manual (p. 117-120) to facilitate convergence: (1) A scale parameter was used and initial models were run with the number of adjustment terms manually set to zero. (2) Initial models included a null model (no covariates) and univariate models with each covariate on its own. (3) Starting with the sim- plest model (null), covariates were added one at a time and covariates which gave the best fit (lowest $\mathrm{AIC}_{\mathrm{c}}$ ) were selected. Forward stepwise selection was conducted by adding additional covariates until there was no decrease in $\mathrm{AIC}_{\mathrm{C}}$. (4) In each step of the modelbuilding procedure, parameter starting values are set manually from the estimates of the previous model. (5) Finally, to check model convergence, MCDS models were compared to a Conventional Distance Sampling (CDS) model with no covariates but the same key function plus adjustment terms. MCDS models should have a likelihood that is as high, or higher, 
than the CDS model. This procedure was carried out for each species, and model fit was assessed with $\mathrm{AIC}_{\mathrm{C}}, \Delta \mathrm{AIC}_{\mathrm{c}}$ (the difference in $\mathrm{AIC}_{\mathrm{c}}$ between a fitted model and the lowest $\mathrm{AIC}_{\mathrm{c}}$ of any model) and $\mathrm{AIC}_{\mathrm{c}} \mathrm{W}$ (the $\mathrm{AIC}_{\mathrm{c}}$ weight, which is the evidence in favor of one model being the actual best model given the set of candidate models which were evaluated) (Burnham \& Anderson 2002).

We developed estimates of $\hat{P}_{a}$ which are relevant to commonly used widths in fixed-width strip transects

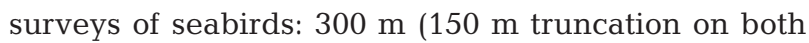
sides) and $200 \mathrm{~m}$ (100 m both sides; e.g. Agler et al. 1998). Parameter estimates of $\hat{P}_{a}$ were obtained for global models (all data and the best fit model) and individual covariate levels using post-stratification by the covariates.

Finally, we assessed the potential effects of sea state on $g(0)$. Lower murrelet densities with increased wave height suggests that $g(0)$ may be reduced by increased sea states (Becker et al. 1997). We compared murrelet encounter rates $(n / L=$ number of clusters counted per distance traveled) for different sea state conditions (Beaufort sea state 0 to 3 ). Encounter rates were calculated for each sea state code (if $>1 \mathrm{~km}$ of survey was conducted at that sea state) on each survey day (unit of analysis). Detection of birds should remain certain or nearly certain at small distances from the line (Buckland et al. 2001), therefore we limited the assessment of encounter rates to birds detected near the line $(\leq 60 \mathrm{~m}$ for murrelets and murres, $\leq 80 \mathrm{~m}$ for cormorants) which corresponds with the 'shoulder' of the histograms (Fig. 1), akin to the distance of 'perfect' detection (Kissling \& Garton 2006). Analysis of variance (ANOVA) was used to compare encounter rates under different sea-state conditions for species with sufficient sample size (murrelet, murre, cormorant).

\section{RESULTS}

Over $3 \mathrm{yr}$ we conducted $1429 \mathrm{~km}$ of line transect surveys $(2004=105 \mathrm{~km} ; 2005=631 \mathrm{~km} ; 2006=$ $693 \mathrm{~km})$. We recorded $>8000$ clusters of seabirds, $70 \%$ of which were marbled murrelets, and most were detected within $80 \mathrm{~m}$ of the transect line (Fig. 1). Three species, pigeon guillemot, pelagic cormorant and gulls, showed some decrease in detection for intervals closer to the transect line, suggesting that these 2 species may exhibit evasive behaviour from approaching boats. However, because the decrease in detections close to the line was not extreme and these are fairly conspicuous species, we assume that most birds were detected before any evasive movements.

\section{Cluster-size bias}

Based on distance vs. cluster-size correlations, pigeon guillemots and pelagic cormorants showed no evidence of cluster-size bias, and common murres and gulls showed no bias when data were truncated at $\leq 150 \mathrm{~m}$ (Table 1). Marbled murrelets and rhinoceros auklets showed extensive cluster-size bias at most truncation distances; this bias was only eliminated for data $<50 \mathrm{~m}$ from the boat. Despite these results, cluster size was identified as an important covariate for pelagic cormorants and pigeon guillemots (Table 2).

\section{Model selection and covariates}

MCDS tested the influence of potential covariates on the fit of detection functions. Table 2 summarizes fit of

Table 1. Evaluation of cluster-size bias when sighting seabird clusters/groups from line-transect surveys. Effects of data truncation on mean cluster size. Pearson's r correlations test the correlation between cluster size and cluster distance from transect line for data truncated at different distances. Significance of Pearson's r with Bonferroni adjustments: ${ }^{*}<0.05$ and ${ }^{* *}<0.01$

\begin{tabular}{|c|c|c|c|}
\hline $\begin{array}{l}\text { Species and truncation } \\
\text { distance }(\mathrm{m})\end{array}$ & $\mathrm{n}$ & $\begin{array}{l}\text { Mean cluster } \\
\text { size } \pm \mathrm{SE}\end{array}$ & $\begin{array}{l}\text { Pearson's } \\
\text { r }\end{array}$ \\
\hline \multicolumn{4}{|l|}{ Marbled murrelet } \\
\hline 300 & 5871 & $2.09 \pm 0.04$ & $0.139^{*}$ \\
\hline 150 & 5738 & $2.05 \pm 0.04$ & $0.103^{* *}$ \\
\hline 100 & 5369 & $1.99 \pm 0.03$ & $0.119^{* *}$ \\
\hline 50 & 3781 & $1.83 \pm 0.04$ & 0.028 \\
\hline \multicolumn{4}{|l|}{ Rhinoceros auklet } \\
\hline 300 & 309 & $1.69 \pm 0.09$ & $0.251^{* *}$ \\
\hline 150 & 307 & $1.66 \pm 0.09$ & $0.179^{* *}$ \\
\hline 100 & 291 & $1.63 \pm 0.08$ & $0.148^{*}$ \\
\hline 50 & 204 & $1.46 \pm 0.07$ & -0.022 \\
\hline \multicolumn{4}{|l|}{ Pigeon guillemot } \\
\hline 300 & 213 & $1.22 \pm 0.04$ & 0.088 \\
\hline 150 & 207 & $1.22 \pm 0.04$ & 0.112 \\
\hline 100 & 192 & $1.22 \pm 0.04$ & 0.178 \\
\hline 50 & 140 & $1.17 \pm 0.03$ & 0.068 \\
\hline \multicolumn{4}{|l|}{ Common murre } \\
\hline 300 & 1008 & $2.13 \pm 0.21$ & $0.342^{* *}$ \\
\hline 150 & 971 & $1.68 \pm 0.11$ & 0.075 \\
\hline 100 & 917 & $1.64 \pm 0.11$ & 0.054 \\
\hline 50 & 665 & $1.51 \pm 0.10$ & 0.042 \\
\hline \multicolumn{4}{|l|}{ Pelagic cormorant } \\
\hline 300 & 800 & $1.23 \pm 0.03$ & 0.074 \\
\hline 150 & 733 & $1.20 \pm 0.03$ & 0.002 \\
\hline 100 & 630 & $1.18 \pm 0.03$ & -0.037 \\
\hline 50 & 359 & $1.17 \pm 0.04$ & -0.113 \\
\hline \multicolumn{4}{|l|}{ Larus spp. } \\
\hline 300 & 145 & $19.88 \pm 4.25$ & $0.229^{*}$ \\
\hline 150 & 133 & $15.71 \pm 3.29$ & 0.032 \\
\hline 100 & 111 & $16.79 \pm 3.81$ & 0.111 \\
\hline 50 & 77 & $16.08 \pm 4.06$ & 0.100 \\
\hline
\end{tabular}


Table 2. Summary of detection function model fits with $\mathrm{AIC}_{\mathrm{c}}$ model selection (see 'Data analysis' for descriptions of Akaike's statistics) and estimated proportion of bird clusters detected $\hat{P}_{a}$ along the transect. Multiple Covariate Distance Sampling (MCDS) analysis used hazard-rate models with no adjustment terms and stepwise addition of covariates. Conventional Distance Sampling (CDS) models were fit to check model convergence. See 'Data analysis' for details. $K=$ total number of parameters in the model. yr: year; obs: observer; ss: sea state; cs: cluster size

\begin{tabular}{|c|c|c|c|c|c|c|}
\hline Species & Model & $K$ & $\mathrm{AIC}_{\mathrm{c}}$ & $\Delta \mathrm{AIC}_{\mathrm{c}}$ & $\Delta \mathrm{AIC}_{\mathrm{c}} \mathrm{W}$ & $\hat{P}_{a}$ \\
\hline \multirow[t]{11}{*}{ Marble murrelet } & (yr, obs) & 9 & 19485.96 & 0.00 & 0.546 & 0.421 \\
\hline & (yr, obs, ss) & 10 & 19487.69 & 1.73 & 0.230 & 0.419 \\
\hline & $(\mathrm{yr}, \mathrm{obs}, \mathrm{cs})$ & 10 & 19487.81 & 1.85 & 0.217 & 0.420 \\
\hline & CDS model (no covariates) & 4 & 19494.87 & 8.91 & 0.006 & 0.410 \\
\hline & (yr) & 4 & 19550.11 & 64.15 & 0.000 & 0.478 \\
\hline & $(\mathrm{yr}, \mathrm{cs})$ & 5 & 19552.14 & 66.18 & 0.000 & 0.478 \\
\hline & $(\mathrm{yr}, \mathrm{ss})$ & 5 & 19552.14 & 66.18 & 0.000 & 0.478 \\
\hline & (obs) & 7 & 19553.73 & 67.77 & 0.000 & 0.479 \\
\hline & Null (no covariates) & 2 & 19554.21 & 68.25 & 0.000 & 0.469 \\
\hline & (CS) & 3 & 19555.89 & 69.93 & 0.000 & 0.471 \\
\hline & $(\mathrm{ss})$ & 3 & 19556.09 & 70.13 & 0.000 & 0.469 \\
\hline \multirow[t]{6}{*}{ Common murre } & CDS model (no covariates) & 6 & 3145.73 & 0.00 & 0.918 & 0.411 \\
\hline & Null (no covariates) & 2 & 3152.09 & 6.36 & 0.038 & 0.451 \\
\hline & $(\mathrm{yr})$ & 3 & 3153.95 & 8.22 & 0.015 & 0.456 \\
\hline & (Cs) & 3 & 3154.08 & 8.35 & 0.014 & 0.452 \\
\hline & (ss) & 3 & 3154.08 & 8.35 & 0.014 & 0.451 \\
\hline & (obs) & 7 & 3161.53 & 15.79 & 0.000 & 0.457 \\
\hline \multirow[t]{11}{*}{ Pelagic cormorant } & $(\mathrm{yr}, \mathrm{cs})$ & 4 & 2749.93 & 0.00 & 0.716 & 0.694 \\
\hline & (yr, cs, ss) & 5 & 2751.96 & 2.03 & 0.260 & 0.694 \\
\hline & (yr, cs, obs) & 8 & 2757.01 & 7.08 & 0.021 & 0.693 \\
\hline & (yr) & 3 & 2761.55 & 11.61 & 0.002 & 0.676 \\
\hline & (yr, ss) & 4 & 2763.55 & 13.62 & 0.001 & 0.676 \\
\hline & (yr, obs) & 7 & 2764.68 & 14.75 & 0.000 & 0.698 \\
\hline & (obs) & 6 & 2771.90 & 21.97 & 0.000 & 0.679 \\
\hline & CDS model (no covariates) & 6 & 2790.76 & 40.83 & 0.000 & 0.536 \\
\hline & Null (no covariates) & 2 & 2801.72 & 51.79 & 0.000 & 0.677 \\
\hline & (ss) & 3 & 2803.69 & 53.76 & 0.000 & 0.677 \\
\hline & $(\mathrm{cs})$ & 3 & 2803.69 & 53.76 & 0.000 & 0.677 \\
\hline \multirow[t]{5}{*}{ Rhinoceros auklet } & CDS model (no covariates) & 2 & 1040.71 & 0.00 & 0.365 & 0.425 \\
\hline & Null (no covariates) & 2 & 1040.71 & 0.00 & 0.365 & 0.425 \\
\hline & (CS) & 3 & 1042.72 & 2.01 & 0.134 & 0.427 \\
\hline & (ss) & 3 & 1042.73 & 2.01 & 0.133 & 0.425 \\
\hline & (obs) & 7 & 1050.90 & 10.18 & 0.002 & 0.430 \\
\hline \multirow[t]{8}{*}{ Pigeon guillemot } & (obs, cs) & 7 & 678.90 & 0.00 & 0.490 & 0.465 \\
\hline & (obs, ss) & 7 & 679.80 & 0.90 & 0.313 & 0.471 \\
\hline & (obs, Cs, ss) & 8 & 681.06 & 2.16 & 0.166 & 0.467 \\
\hline & (obs) & 6 & 684.48 & 5.58 & 0.030 & 0.396 \\
\hline & $(\mathrm{CS})$ & 3 & 709.77 & 30.87 & 0.000 & 0.512 \\
\hline & CDS model (no covariates) & 2 & 709.88 & 30.98 & 0.000 & 0.513 \\
\hline & Null (no covariates) & 2 & 709.88 & 30.98 & 0.000 & 0.513 \\
\hline & (ss) & 3 & 711.93 & 33.03 & 0.000 & 0.515 \\
\hline \multirow[t]{5}{*}{ Larus spp. } & CDS model (no covariates) & 2 & 498.86 & 0.00 & 0.368 & 0.442 \\
\hline & Null (no covariates) & 2 & 498.86 & 0.00 & 0.368 & 0.442 \\
\hline & (CS) & 3 & 500.95 & 2.09 & 0.130 & 0.442 \\
\hline & (ss) & 3 & 500.95 & 2.09 & 0.130 & 0.442 \\
\hline & (obs) & 6 & 507.45 & 8.58 & 0.005 & 0.442 \\
\hline
\end{tabular}

models, comparing models with and without covariates. For 3 species (murres, auklets, gulls) the best fit model contained no covariates (null model). Observer was included as a covariate in the best fit model for murrelets and guillemots, and year was included in the best model for murrelets and cormorants. CDS models were included in model comparisons to check for model convergence, i.e. MCDS models should have a likelihood that is as high, or higher, than the CDS model (i.e. $\mathrm{AIC}_{\mathrm{c}}$ of $\mathrm{CDS}$ model is $\leq \mathrm{AIC}_{\mathrm{c}}$ of best fit MCDS model). Thus, model convergence was achieved for all species except common murre (Table 3), which nonetheless showed no improvement on the null model by addition of covariates. 
Table 3. Parameter estimates for detectability of seabirds surveyed using line transects. $\hat{P}_{a}$ estimates from program Distance indicate the proportion of birds on the water detected for 150 and $100 \mathrm{~m}$ data truncation which corresponds to 300 and $200 \mathrm{~m}$ wide strip transects respectively. Parameter estimates are provided only for covariates which were identified as important predictors in the best fit models for each species (Table 2). Density estimates are not provided for individual observers because these values are additive for higher levels (year or global model). Global $\hat{P}_{a}$ estimates are from the best fit models with covariates (Table 2) and global density estimates are calculated from the weighted means based on effort per year

\begin{tabular}{|c|c|c|c|c|c|c|c|c|}
\hline \multirow[b]{2}{*}{ Species and level } & \multicolumn{4}{|c|}{$150 \mathrm{~m}$ data truncation } & \multicolumn{4}{|c|}{$-100 \mathrm{~m}$ data truncation- } \\
\hline & $\begin{array}{l}\text { No. of } \\
\text { clusters }\end{array}$ & $\hat{P}_{a}$ & $95 \%$ CI & $\begin{array}{l}\text { Density estimate } \\
\quad \text { (birds } \mathrm{km}^{-2} \text { ) }\end{array}$ & $\begin{array}{l}\text { No. of } \\
\text { clusters }\end{array}$ & $\hat{P}_{a}$ & $95 \%$ CI & $\begin{array}{l}\text { Density estimate } \\
\quad \text { (birds } \mathrm{km}^{-2} \text { ) }\end{array}$ \\
\hline \multicolumn{9}{|l|}{ Marbled murrelet } \\
\hline Global & 5738 & 0.421 & $0.412-0.429$ & 54.07 & 5369 & 0.529 & $0.519-0.540$ & 58.81 \\
\hline 2004 & 479 & 0.442 & $0.346-0.564$ & 69.67 & 394 & 0.539 & $0.411-0.707$ & 68.20 \\
\hline Obs 1 & 178 & 0.514 & $0.360-0.735$ & & 145 & 0.628 & $0.430-0.917$ & \\
\hline Obs 2 & 301 & 0.397 & $0.284-0.555$ & & 249 & 0.482 & $0.327-0.710$ & \\
\hline 2005 & 2288 & 0.393 & $0.381-0.404$ & 47.87 & 2270 & 0.548 & $0.527-0.570$ & 50.33 \\
\hline Obs 1 & 809 & 0.439 & $0.417-0.461$ & & 799 & 0.628 & $0.593-0.665$ & \\
\hline Obs 3 & 494 & 0.228 & $0.209-0.250$ & & 494 & 0.330 & $0.297-0.368$ & \\
\hline Obs 4 & 985 & 0.417 & $0.417-0.461$ & & 977 & 0.616 & $0.588-0.644$ & \\
\hline 2006 & 2971 & 0.587 & $0.568-0.607$ & 48.03 & 2705 & 0.654 & $0.601-0.711$ & 55.59 \\
\hline Obs 1 & 1145 & 0.535 & $0.506-0.566$ & & 1069 & 0.570 & $0.489-0.666$ & \\
\hline Obs 2 & 52 & 0.285 & $0.100-0.813$ & & 45 & 0.375 & $0.116-1.000$ & \\
\hline Obs 5 & 754 & 0.603 & $0.568-0.640$ & & 685 & 0.810 & $0.757-0.866$ & \\
\hline Obs 6 & 1020 & 0.625 & $0.591-0.661$ & & 906 & 0.714 & $0.624-0.816$ & \\
\hline \multicolumn{9}{|l|}{ Common murre } \\
\hline Global & 941 & 0.451 & $0.422-0.483$ & 7.37 & 891 & 0.537 & $0.478-0.604$ & 8.54 \\
\hline \multicolumn{9}{|l|}{ Pelagic cormorant } \\
\hline Global & 723 & 0.694 & $0.664-0.724$ & 2.83 & 621 & 0.892 & $0.868-0.916$ & 2.79 \\
\hline 2005 & 441 & 0.604 & $0.569-0.641$ & 4.02 & 409 & 0.847 & $0.815-0.880$ & 3.98 \\
\hline 2006 & 282 & 0.903 & $0.870-0.937$ & 1.74 & 212 & 0.995 & $0.984-1.000$ & 1.71 \\
\hline \multicolumn{9}{|l|}{ Rhinoceros auklet } \\
\hline Global & 307 & 0.425 & $0.369-0.489$ & 2.40 & 291 & 0.516 & $0.401-0.665$ & 2.75 \\
\hline \multicolumn{9}{|l|}{ Pigeon guillemot } \\
\hline Global & 202 & 0.465 & $0.414-0.522$ & 1.09 & 187 & 0.602 & $0.541-0.671$ & 1.13 \\
\hline Obs 1 & 92 & 0.474 & $0.407-0.552$ & & 87 & 0.642 & $0.562-0.734$ & \\
\hline Obs 3 & 19 & 0.257 & $0.169-0.392$ & & 19 & 0.339 & $0.225-0.510$ & \\
\hline Obs 4 & 34 & 0.377 & $0.284-0.499$ & & 34 & 0.544 & $0.423-0.699$ & \\
\hline Obs 5 & 13 & 0.513 & $0.332-0.792$ & & 11 & 0.542 & $0.327-0.899$ & \\
\hline Obs 6 & 44 & 0.803 & $0.697-0.923$ & & 36 & 1.000 & $0.941-1.000$ & \\
\hline \multicolumn{9}{|l|}{ Larus spp. } \\
\hline Global & 129 & 0.442 & $0.277-0.705$ & 10.90 & 108 & 0.564 & $0.345-0.921$ & 11.42 \\
\hline
\end{tabular}

\section{Parameter estimates}

We developed parameter estimates of $\hat{P}_{a}$, proportion of clusters detected, for each species and significant covariates identified in Table 2 . Table 3 provides parameter estimates for data truncation at 150 and $100 \mathrm{~m}$, i.e. 300 and $200 \mathrm{~m}$ wide transects respectively. For $300 \mathrm{~m}$ wide transects, $\hat{P}_{a}$ estimates suggest that generally between 40 and $60 \%$ of alcid groups are detected, apparently unrelated to size or conspicuousness of the species. For the largest species, $69 \%$ of cormorants were detected but surprisingly only $44 \%$ of gulls were detected. $\hat{P}_{a}$ estimates varied considerably among years (murrelets, 0.393 to 0.587 ; cormorants, 0.604 to 0.903 ) and observers (murrelets, 0.228 to 0.625 ; guillemots, 0.377 to 0.803 ). For $200 \mathrm{~m}$ wide transects, $\hat{P}_{a}$ estimates increased by about 0.1 for most species but as much as 0.2 for cormorants.

\section{Sea state effects on $g(0)$}

Comparison of cluster encounter rates of birds near the transect line can provide some indication of sea state effects on $g(0)$. From $1429 \mathrm{~km}$ of transects (54 d), $22 \%(\mathrm{n}=29 \mathrm{~d}), 43 \%(\mathrm{n}=44), 29 \%(\mathrm{n}=32)$ and $6 \%(\mathrm{n}=$ 14) were conducted during sea states $0,1,2$, and 3 respectively. Sea state effects were variable among species (Fig. 2). Encounter rates did not vary among sea states for common murres (ANOVA: $F_{3,115}=0.679$, $\mathrm{p}=0.567)$ or pelagic cormorants $\left(F_{3,115}=0.125, \mathrm{p}=\right.$ 0.945). Sea state did affect encounter rates for marbled murrelets $\left(F_{3,115}=2.716, \mathrm{p}=0.048\right)$ with significant post-hoc tests (Tukey's HSD) showing higher encounter rates during sea state 0 (mean $3.93 \pm 0.59 \mathrm{SE}$ clusters $\left.\mathrm{km}^{-1}\right)$ compared to sea state $2(2.22 \pm 0.32, \mathrm{p}=$ $0.036)$ but not sea states $1(2.65 \pm 0.33, \mathrm{p}=0.132)$ or $3(3.03 \pm 0.70, p=0.671)$. This suggests the potential for 


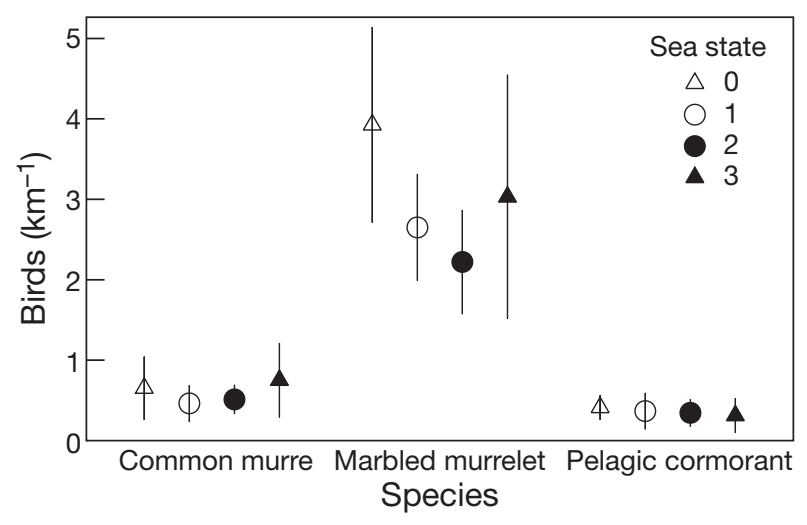

Fig. 2. Uria aalge, Brachyramphus marmoratus, and Phalacrocorax pelagicus. Effects of Beaufort sea state on mean encounter rate of bird clusters along a transect line. Includes only bird clusters near the transect line $(\leq 60 \mathrm{~m}$ for murres and murrelets; $\leq 80 \mathrm{~m}$ for cormorants). Bars indicate $95 \% \mathrm{CI}$

$g(0)<1$ for murrelets, but not murres or cormorants, when sea state increases.

\section{DISCUSSION}

\section{Detection of seabirds}

Reliable assessment of animal densities is an integral part of wildlife research (Thompson 2002, Braun 2005). Accurate density estimates allow for robust population estimations and population trend analysis which is essential for the conservation and management of threatened marine species (Slooten et al. 2004, Gomez de Segura et al. 2006, Slooten et al. 2006). Although it has long been recognized that the detectability of seabirds decreases with distance from a transect line (Dixon 1977), few seabird studies have tried to quantify this. Previous studies have developed methods to account for detectability of birds in flight (e.g. Spear et al. 2004, Hyrenbach et al. 2007). Our study provides a comprehensive analysis of detectability of birds on the water.

Our results suggest that, even within $150 \mathrm{~m}$ of the transect line in relatively calm conditions, anywhere between 25 and $90 \%$ of bird groups on the water may be detected, depending on species, year and/or observer. Marbled murrelets were the smallest species evaluated and estimates of detection probability among years ranged from 39 to $59 \%$ with 150 m truncation and 54 to $65 \%$ with $100 \mathrm{~m}$ truncation. Becker et al. (1997) reported 49 to $66 \mathrm{~m}$ effective strip widths from $160 \mathrm{~m}$ truncated data which convert into 31 to $41 \%$ detection. With $120 \mathrm{~m}$ data truncation, Peery et al. (2006) had detection probabilities ranging from 44 to $55 \%$ (calculated from $f(0)$ estimates in their Appendix
Table 2). Raphael et al. (2007) had detection probabilities of $55 \%$ (175 m truncation; calculated from $f(0)$ estimates in their Appendix 4). Therefore, across multiple studies, marbled murrelet detection probabilities appear to vary considerably between 40 and $65 \%$, partially depending on transect width.

Conspicuousness can affect the detection and counting of animals along transects (Ryan \& Cooper 1989, Spear et al. 2004). Marine mammal surveys frequently incorporate correction factors for different species (Forney \& Barlow 1998), but there are few published data on detection probabilities for seabirds other than marbled murrelets. Hyrenbach et al. (2001) used distance sampling to count shearwater carcasses for mortality estimates and found effective strip widths of 42 to $55 \mathrm{~m}$, which are comparable to estimates for live murrelets (Becker et al. 1997). Although several studies have recommended the use of distance sampling for seabird transects (Hyrenbach et al. 2001, Camphuysen et al. 2004, Huettmann \& Diamond 2006), we found no published detection functions for other seabird species. Our data demonstrate that detectability varied among species, though most alcids showed similar detection functions. Pelagic cormorants were detectable over much greater distances likely owing to their size and height. Nevertheless, despite the apparent conspicuousness of cormorants, year was still an important covariate when modeling detection functions, suggesting that detectability is not perfect even for this relatively large species. Strip-transects also show speciesspecific differences in seabird detectability (Hyrenbach et al. 2007).

\section{Effects of covariates}

Systematic biases in counting procedures can be an important source of error in estimating bird abundance (Thompson 2002) but inclusion of covariates can minimize the heterogeneity in detection probabilities (Marques \& Buckland 2003). In our study, we assessed variability in detection functions with the inclusion several covariates: year, observer, sea state and cluster size.

Year was an important covariate for murrelets and cormorants but not murres. Likewise, other studies have observed differences in detection functions among years for marbled murrelets (Becker et al. 1997, Peery et al. 2004, 2006). The significance of year as a covariate could be explained by annual changes in bird abundance and distribution in the study area. Changing distribution of prey from one year to the next can significantly alter the distribution and aggregation of seabirds (Davoren 2000). In years when seabirds are more dispersed or in smaller groups, they may be harder to detect and thus the detection functions may 
differ. However, this effect should have been accounted for by the cluster size covariate, thus, the year effect may also be picking up differences in covariates that were not measured or included in the analysis. The detectability of birds during transects may also decrease as a function of decreasing bird density (Ostrand et al. 1998). In our study, murrelet and cormorant densities varied annually, but high density years did not necessarily result in higher detectability (Table 3).

Differences among observers' abilities to detect birds in vessel-based seabird surveys may sometimes be large (van der Meer \& Camphuysen 1996). Observer biases may result from differences in observer's visual acuity, attentiveness and experience (Ralph \& Scott 1981, Laake et al. 1997). Observers may even show differences in detecting birds on the transect line, $g(0)$, where birds should be easiest to detect (Evans Mack et al. 2002). Observer was an important covariate in another murrelet study (Peery et al. 2006) and for 2 species in this study. These biases appear to be unrelated to experience in our study since $\hat{P}_{a}$ estimates for inexperienced observers (Obs 3,4,5) overlapped with those of experienced observers $(3+$ yrs experience: Obs 1, 2, 6). Despite training, observer biases may have resulted from general over- or underestimation of distances by particular individuals (Obs 3 , lowest $\hat{P}_{a}$ estimates; Obs 6 highest $\hat{P}_{a}$ estimates). However, if measurement error was the primary source of observer bias, we would have expected observer to be a significant covariate for all species; this was not the case. Observer 3 also had the lowest encounter rates (no. of clusters, Table 3), which is consistent with lower detection rates. Thus it is likely that there are real differences in the way observers searched or were able to identify birds. Observer differences are quite real and coping with them is one of the advantages of distance sampling.

Winds and associated waves can affect observers' abilities to detect animals at sea. This may be particularly true for smaller cryptic species such as marine birds (Evans Mack et al. 2002, Peery et al. 2006) or turtles (Beavers \& Ramsey 1998). Surprisingly, sea state was not included in the best models for any species in our study. The lack of significance for sea state as a covariate simply means that the proportion of birds detected $\hat{P}_{a}$ does not change. This suggests that even when fewer birds overall may be detected in poor viewing (e.g. 10 birds) vs. good viewing conditions (20 birds), the proportion of birds detected near the transect line vs. farther from the transect line could remain the same (9:1 during poor conditions vs. 18:2 during good viewing conditions). Thus $\hat{P}_{a}$ may remain unaffected by sea state, but $g(0)$ can still decrease with increased sea state.
This study was not designed explicitly to provide estimates of $g(0)$. Alternatively, comparisons of bird densities near the transect line provide some evidence of how $g(0)$ may vary with sea state. Densities of murrelets encountered on transects decreased for sea states 2 to 3 compared to sea states 0 to 1 in California (Becker et al. 1997). Similarly, for murrelets, we observed decreased encounter rates in sea states $>0$, though there was no statistical difference between the calmest conditions (0) and the roughest (3). Increased sea states may affect the behaviour of birds making them less detectable: higher sea state increases dive bout duration of murrelets (Jodice \& Collopy 1999) or the proportion of time spent at sea for species that frequently loaf or roost on land (cormorants, gulls, guillemots). If the latter is true, or birds move away from the study area during rough conditions, then using encounter rates to test $g(0)$ is inappropriate. Other factors, such as observer experience or animal group size, may also cause $g(0)<1$ (Laake et al. 1997, Evans Mack et al. 2002). More effort should be placed on validating the critical assumption $g(0)=1$ for seabirds. Our surveys sampled only relatively calm seas (Beaufort scale $\leq 3$ ) and it is likely that sea state would greatly affect detectability in rougher seas. Larger vessels frequently continue surveys in Beaufort sea-states $>3$. The multiple observer approach used by Evans Mack et al. (2002) is likely the best way to test assumptions of $g(0)$ under a variety of conditions.

\section{Implications for at sea surveys}

Estimates of $\hat{P}_{a}$ (Table 3 ) are potentially useful as correction factors for fixed-width strip transects. However, we do not recommend that they be used as such because these estimates varied considerably among years and observers and therefore are not directly transferable to other studies. Moreover, our surveys were conducted from a slow-moving small boat and detectability will likely vary with boat size (observer height above sea) and speed. Boat size and speed may also affect the extent to which birds are repelled (or attracted) and the distance at which this might happen (Hyrenbach 2001, Hyrenbach et al. 2007, Bellefleur et al. 2009). Furthermore, correction factors are not directly applicable to all boat transect surveys because environmental factors will differ among regions and habitat types. We tested only effects of sea state, but wind direction, sun glare or water clarity are also known to affect detectability (Briggs \& Hunt 1981, Hyrenbach et al. 2001, Evans Mack et al. 2002).

Parameter estimates for $150 \mathrm{~m}$ truncation (300 m strip sampled on both sides of the vessel) are not applicable to surveys that follow the Tasker et al. (1984) 
protocols for $300 \mathrm{~m}$ strip transects which record birds only on one side of the vessel. Birds, such as alcids, that spend a considerable amount of time on the water (Tremblay et al. 2003) could be substantially underestimated with single-sided $300 \mathrm{~m}$ wide transects. In this study, $<4 \%$ of all alcids and $<10 \%$ of gulls and cormorants were detected between 150 and 300 m (sample sizes in Table 1) suggesting extremely low detectability in this distance band. For flying birds, a $300 \mathrm{~m}$, or wider, single-sided strip may be suitable for many species (Hyrenbach et al. 2007), but smaller and more cryptic species are underestimated with standard strip transects (Spear et al. 2004).

Marine mammal researchers routinely use distance sampling when estimating densities and population size (Forcada et al. 2004, Slooten et al. 2006). We recognize 3 main reasons why seabird biologists have been reluctant to incorporate distance sampling in survey protocols. (1) Although accurate density estimation is worthwhile, trend analysis based on long-term datasets is also important. Many long-term seabird survey programs have used fixed-width transects (e.g. Pyle 2007) and there are concerns over comparability between methods. Implementing distance sampling in the field still allows one to analyze the data as strip transects (of any desired width), but the opposite is not true. Nevertheless, it is possible that observers using distance sampling might inadvertently focus greater attention on birds near the vessel given the strong emphasis in distance sampling of having $g(0)=1$, whereas observers doing strip transects might be more likely to see distant birds. This potential bias in observer effect needs to be more fully investigated if data from the 2 methods are to be compared or combined.

(2) Distance sampling techniques are more readily applicable to birds on the water than to birds in flight. This is particularly important for surveys of pelagic species that spend a considerable amount of time on the wing. A variety of techniques are employed to assess densities of birds in flight (e.g. Tasker et al. 1984, Spear et al. 2004, Hyrenbach et al. 2007). Application of distance sampling to birds in flight is a major obstacle that must be addressed.

(3) Distance sampling is effort intensive and seabirds are frequently encountered in patches of high densities, making recording of distances to individual birds/ flocks difficult. Experienced observers have claimed that true distance sampling techniques are not practical to record seabirds at sea; e.g. Hyrenbach et al. (2001, p 15) commented that distance sampling 'should be employed only when seabirds are sparse and nonmobile, and enough observers are available to estimate the perpendicular ranges to sightings and to monitor birds directly on the track'. We agree that recording exact distance to all groups is not practical in many situations. Instead, some seabird programs use grouped (binned) distances rather than ungrouped (exact) distances for bird detection (Komdeur et al. 1992, Camphuysen et al. 2004). Yet in situations where birds occur in extremely high densities (e.g. rafts of shearwaters in Alaska), the errors associated with distance sampling (group size and distance estimation) may outweigh the uncertainty associated with strip transects. In these high density situations, narrow strip transects, which minimize detectability bias and allow for more precise counting of many individuals, may provide the most accurate density estimates.

\section{CONCLUSIONS}

Our study shows clearly that standard strip-transect methods underestimate densities of birds on the water. Based on our results, we make the following conclusions and recommendations:

- The assumption of perfect detection within a striptransect is very unlikely unless the strip is very narrow (e.g. 50 to $100 \mathrm{~m}$ ).

- Because year and observer were important predictors for some species, a single species-specific correction factor is not applicable to all surveys. Collection of distance data can be used to estimate surveyspecific detection probability.

- Observer differences in this study appear to be related to observer search and detection ability rather than measurement error. Distance sampling is only useful if distances are measured accurately, thus, observer training and testing is important.

- Distance sampling offers the ability to identify and correct for detectability biases which may include weather, species, observers and platform types.

Additionally we identify 4 important considerations that must be addressed for widespread use of distance sampling with seabird surveys:

- Appropriate methods should be developed to apply distance sampling with birds in flight.

- For some species, $g(0)$ may be $<1$ and is likely affected by weather conditions, platform types, and avoidance (or attraction) behaviour of birds. It will be important to conduct independent observer experiments to evaluate $g(0)$.

- Techniques must be amenable to situations where birds occur in very high densities.

- Distance sampling methods should ensure that results are compatible with long-term survey programs using strip transects.

Distance sampling offers the ability to correct for important survey biases among platforms, species and regions which will help increase the precision of population estimates and make survey results comparable 
among study areas. This is crucial for merging data sets and findings globally. Surveys that do not account for detectability issues in density estimation can be biased, which may interfere with population assessment (Norvell et al. 2003). Studies analyzing population trends or comparing the distributions of birds relative to biophysical landscapes could, arguably, work adequately with relative abundance indices (strip transects) rather than distance sampling density estimates. Nevertheless, the use of distance sampling to correct for detectability issues should increase the accuracy and precision of all transect-based studies of seabirds.

Acknowledgements. Many thanks to T. Haynes, N. Hentze, H. Milligan, S. Wong, and N. Watson for their excellent field assistance. The Canadian Coast Guard kindly provided accommodation at Carmanah and Pachena Light Stations and we warmly thank lightkeepers J. and J. Etzkorn and S. Bell for their help. We thank Parks Canada, and especially B. Hansen and WCT wardens, for their ongoing collaboration and help. We are extremely grateful to the Simon Fraser University (D. Lank) and the Canadian Wildlife Service (D. Bertram) for the loan of a boat and related equipment. Funding was provided by NSERC Canada (Canada Graduate Scholarship to R.A.R., Discovery Grant to A.E.B.), Science Horizons Youth Internship Program (Environment Canada), Endangered Species Recovery Fund (WWF and CWS), BC Forest Science Program, and the Society of Canadian Ornithologists (Taverner Award). Thanks to F. Huettmann, D. Fifield, C. Gjerdrum and anonymous reviewers for insightful discussion and comments which improved this manuscript.

\section{LITERATURE CITED}

Agler BA, Kendall SJ, Irons DB (1998) Abundance and distribution of marbled and Kittlitz's murrelets in southcentral and southeast Alaska. Condor 100:254-265

Bächler E, Liechti F (2007) On the importance of $g(0)$ for estimating bird population densities with standard distancesampling: implications from a telemetry study and a literature review. Ibis 149:693-700

Beavers SC, Ramsey FL (1998) Detectability analysis in transect surveys. J Wildl Manage 62:948-957

Becker BH, Beissinger SR, Carter HR (1997) At-sea density monitoring of marbled murrelets in central California: methodological considerations. Condor 99:743-755

Bellefleur D, Lee P, Ronconi RA (2009) The impact of recreational boat traffic on marbled murrelets (Brachyramphus marmoratus). J Environ Manag 90:531-538

Braun CE (ed) (2005) Techniques for wildlife investigations and management. 6th edition. The Wildlife Society, Bethesda, MD

Brennan K (2000) Testing assumptions of line transect methodology for marbled murrelets at sea using an independent observer. MSc thesis, University of Washington, Seattle, WA

Briggs KT, Hunt GL (1981) Seabirds: details of strip censusing techniques. In: Briggs KT, Chu EW, Lewis DB, Tyler WB, Pitman RL, Hunt GL Jr. (eds) Summary report, 1975-1978: Marine mammal and seabird survey of the Southern California Bight area. US Department of Commerce, National Technical Information Service Report PB 81-248-197, Springfield, VA, p 257-276
Brown RGB, Nettleship DN, Germain P, Tull CE, Davis T (1974) Atlas of eastern Canadian seabirds. Canadian Wildlife Service, Sackville, NB

Buckland ST, Anderson DR, Burnham KP, Laake JL, Borchers DL, Thomas L (2001) Introduction to distance sampling: estimating abundance of biological populations. Oxford University Press, Oxford

Buckland ST, Anderson DR, Burnham KP, Laake JL, Borchers DL, Thomas L (2004) Advanced distance sampling. Oxford University Press, Oxford

> Burger AE, Hitchcock CL, Davoren GK (2004) Spatial aggregations of seabirds and their prey on the continental shelf off SW Vancouver Island. Mar Ecol Prog Ser 283:279-292

- Burger AE, Hitchcock CL, Stewart EA, Davoren GK (2008) Coexistence and spatial distributions of marbled murrelets (Brachyramphus marmoratus) and other alcids off Southwest Vancouver Island, British Columbia. Auk 125:192-204

Burnham KP, Anderson DR (2002) Model selection and multimodel inference: a practical information-theoretic approach. Springer-Verlag, New York

Burnham KP, Anderson DR, Laake JL (1980) Estimation of density from line transect sampling of biological populations. Wildl Monogr 72:1-202

Camphuysen CJ, Fox AD, Leopold MF, Petersen IK (2004) Towards standardised seabirds at sea census techniques in connection with environmental impact assessments for offshore wind farms in the UK. Report No. COWRIE BAM-02-2002, Royal Netherlands Institute for Sea Research, Texel

> Davoren GK (2000) Variability in foraging in response to changing prey distributions in rhinoceros auklets. Mar Ecol Prog Ser 198:283-291

Dixon TJ (1977) Distance at which sitting birds can be seen at sea. Ibis 119:372-375

Evans Mack D, Raphael MG, Laake JL (2002) Probability of detecting marbled murrelets at sea: effects of single versus paired observers. J Wildl Manage 66:865-873

> Forcada J, Gazo M, Aguilar A, Gonzalvo J, Fernández-Contreras M (2004) Bottlenose dolphin abundance in the NW Mediterranean: addressing heterogeneity in distribution. Mar Ecol Prog Ser 275:275-287

Forney KA, Barlow J (1998) Seasonal patterns in the abundance and distribution of California cetaceans, 1991-1992. Mar Mamm Sci 14:460-489

> Gomez de Segura A, Tomas J, Pedraza SN, Crespo EA, Raga JA (2006) Abundance and distribution of the endangered loggerhead turtle in Spanish Mediterranean waters and the conservation implications. Anim Conserv 9:199-206

Heinemann D (1981) A rangefinder for pelagic bird censusing. J Wildl Manage 45:489-493

Huettmann F, Diamond AW (2006) Large-scale effects on the spatial distribution of seabirds in the Northwest Atlantic. Landscape Ecol 21:1089-1108

Hyrenbach KD (2001) Albatross response to survey vessels: implications for studies of the distribution, abundance, and prey consumption of seabird populations. Mar Ecol Prog Ser 212:283-295

Hyrenbach KD, Baduini CL, Hunt GL Jr (2001) Line transect estimates of short-tailed shearwater Puffinus tenuirostris mortality in the south-eastern Bering Sea, 1997-1999. Mar Ornithol 29:11-18

Hyrenbach KD, Henry MF, Morgan KH, Welch DW, Sydeman WJ (2007) Optimizing the width of strip transects for seabird surveys from vessels of opportunity. Mar Ornithol $35: 29-37$

$>$ Jespersen P (1924) The frequency of birds over the high Atlantic Ocean. Nature 114:281-283 
Jodice PGR, Collopy MW (1999) Diving and foraging patterns of marbled murrelets (Brachyramphus marmoratus): testing predictions from optimal-breathing models. Can J Zool 77:1409-1418

Kissling ML, Garton EO (2006) Estimating detection probability and density from point-count surveys: a combination of distance and double-observer sampling. Auk 123:735-752

Komdeur J, Bertelsen J, Cracknell G (1992) Manual for Aeroplane and Ship Surveys of Waterfowl and Seabirds. IWRB Special Publ. No. 19, National Environmental Research Institute, Kalø.

Kulbicki M, Sarramegna S (1999) Comparison of density estimates derived from strip transect and distance sampling for underwater visual censuses: a case study of Chaetodontidae and Pomacanthidae. Aquat Living Resour 12: 315-325

Laake JL, Calambokidis J, Osmek SD, Rugh DJ (1997) Probability of detecting harbor porpoise from aerial surveys: Estimating $g(0)$. J Wildl Manage 61:63-75

le Mar K, Southwell C, McArthur C (2001) Evaluation of linetransect sampling to estimate nocturnal densities of macropods in open and closed habitats. Wildl Res 28:9-16

Marques FFC, Buckland ST (2003) Incorporating covariates into standard line transect analyses. Biometrics 59:924-935

Marsh H, Sinclair DF (1989) Correcting for visibility bias in strip transect aerial surveys of aquatic fauna. J Wildl Manage 53:1017-1024

Norvell RE, Howe FP, Parrish JR (2003) A seven-year comparison of relative-abundance and distance-sampling methods. Auk 120:1013-1028

Ostrand WD, Drew GS, Suryan RM, McDonald LL (1998) Evaluation of radio-tracking and strip transect methods for determining foraging ranges of black-legged kittiwakes. Condor 100:709-718

Peery MZ, Beissinger SR, Newman SH, Becker BH, Burkett E, Williams TD (2004) Individual and temporal variation in inland flight behavior of Marbled Murrelets: implications for population monitoring. Condor 106:344-353

Peery MZ, Becker BH, Beissinger SR (2006) Combining demographic and count-based approaches to identify source-sink dynamics of a threatened seabird. Ecol Appl 16:1516-1528

Peery MZ, Becker BH, Beissinger SR (2007) Age ratios as estimators of productivity: Testing assumptions on a threatened seabird, the marbled murrelet (Brachyramphus marmoratus). Auk 124:224-240

Pyle P (2007) Standardizing at-sea monitoring programs for marine birds, mammals, other organisms, debris, and vessels, including recommendations for West-Coast National Marine Sanctuaries. Gulf of the Farallones National Marine Sanctuary, San Francisco, CA.

Ralph CJ, Scott JM (eds) (1981) Estimating numbers of terrestrial birds. Studies in Avian Biology 6. Cooper Ornithological Society, Lawrence, KS

Raphael MG, Evans Mack D, Wilk RJ (1999) Sampling mar-

Editorial responsibility: William Sydeman,

Petaluma, California, USA bled murrelets at sea: tests of survey methods and designs. www.reo.gov/monitoring/reports/murrelet/pnw_atsea.pdf

Raphael MG, Baldwin J, Falxa GA, Huff $\mathrm{MH}$ and others (2007) Regional population monitoring of the marbled murrelet: field and analytical methods. Gen Tech Rep PNW-GTR-716, US Department of Agriculture, Forest Service, Pacific Northwest Research Station, Portland, OR

RIC (2001) Inventory methods for marbled murrelets in marine and terrestrial habitats: standards for components of British Columbia's biodiversity, No. 10, Version 2.0. Ministry of Environment, Lands and Parks, Resources Inventory Committee, Victoria, BC

Ronconi RA, Burger AE (2008) Limited foraging flexibility: increased foraging effort by a marine predator does not buffer against scarce prey. Mar Ecol Prog Ser 366: 245-258

Rosenstock SS, Anderson DR, Giesen KM, Leukering T, Carter MF (2002) Landbird counting techniques: current practices and an alternative. Auk 119:46-53

Ryan PG, Cooper J (1989) Observer precision and bird conspicuousness during counts of birds at sea. S Afr J Mar Sci 8:271-276

Slooten E, Dawson SM, Rayment WJ (2004) Aerial surveys for coastal dolphins: abundance of Hector's dolphins off the South Island west coast, New Zealand. Mar Mamm Sci 20:477-490

> Slooten E, Dawson S, Rayment W, Childerhouse S (2006) A new abundance estimate for Maui's dolphin: What does it mean for managing this critically endangered species? Biol Conserv 128:576-581

Spear LB, Ainley DG, Denise Hardesty B, Howell SNG, Webb SW (2004) Reducing biases affecting at-sea surveys of seabirds: use of multiple observer teams. Mar Ornithol 32:147-157

Tasker ML, Jones PH, Dixon T, Blake BF (1984) Counting seabirds at sea from ships: a review of methods employed and a suggestion for a standardized approach. Auk 101: $567-577$

Thomas L, Laake JL, Strindberg S, Marques FFC and others (2006) Distance 5.0. Release 2. Research Unit for Wildlife Population Assessment, University of St. Andrews. www. ruwpa.st-and.ac.uk/distance/.

Thompson WL (2002) Towards reliable bird surveys: accounting for individuals present but not detected. Auk 119: $18-25$

Tremblay Y, Cherel Y, Oremus M, Tveraa T, Chastel O (2003) Unconventional ventral attachment of time-depth recorders as a new method for investigating time budget and diving behaviour of seabirds. J Exp Biol 206:1929-1940

> van der Meer J, Camphuysen CJ (1996) Effect of observer differences on abundance estimates of seabirds from shipbased strip transect surveys. Ibis 138:433-437

Wynne-Edwards VC (1935) On habits and distribution of birds on the North Atlantic. Proc Boston Soc Nat Hist 40: 233-346

Submitted: January 21, 2008; Accepted: November 13, 2008

Proofs received from author(s): January 15, 2009 